\title{
Turning Agricultural Wastes into Biomaterials: Assessing the Sustainability of Scenarios of Circular Valorization of Corn Cob in a Life-Cycle Perspective
}

\author{
Enrica Santolini ${ }^{+}\left(\mathbb{D}\right.$, Marco Bovo $^{+}\left(\mathbb{D}\right.$, Alberto Barbaresi $^{\dagger}$, Daniele Torreggiani and Patrizia Tassinari $^{*}$ \\ Department of Agricultural and Food Sciences, Alma Mater Studiorum, University of Bologna, Viale G. Fanin 48, \\ 40127 Bologna, Italy; enrica.santolini2@unibo.it (E.S.); marco.bovo@unibo.it (M.B.); \\ alberto.barbaresi@unibo.it (A.B.); daniele.torreggiani@unibo.it (D.T.) \\ * Correspondence: patrizia.tassinari@unibo.it \\ † These authors contributed equally to this work.
}

check for updates

Citation: Santolini, E.; Bovo, M.; Barbaresi, A.; Torreggiani, D.; Tassinari, P. Turning Agricultural Wastes into Biomaterials: Assessing the Sustainability of Scenarios of Circular Valorization of Corn Cob in a Life-Cycle Perspective. Appl. Sci. 2021, 11, 6281. https://doi.org/ 10.3390/app11146281

Academic Editors: Elza Bontempi, Stefania Pindozzi and Elena Cervelli

Received: 14 May 2021

Accepted: 2 July 2021

Published: 7 July 2021

Publisher's Note: MDPI stays neutral with regard to jurisdictional claims in published maps and institutional affiliations.

Copyright: (c) 2021 by the authors. Licensee MDPI, Basel, Switzerland. This article is an open access article distributed under the terms and conditions of the Creative Commons Attribution (CC BY) license (https:/ / creativecommons.org/licenses/by/ $4.0 /)$.
Abstract: Circular economy plays a key role in increasing the sustainability of the agricultural sector, given the countless possibilities of transforming crop residues and recycling precious resources. The maize cultivation process produces a significant amount of residual organic materials, commonly left on the field, as a soil conditioner and source of nutrients even if some parts, such as the cob, play a minor role in these actions. The solutions for the valorization of this remnant depend on economic and environmental factors and the evaluation of the environmental performances of the processes in a life-cycle perspective is important to compare the overall sustainability of the valorization alternatives, maximizing their environmental added value. This work reports the results of Life Cycle Analysis, from cradle-to-gate of corn cob valorized as a raw material in two scenarios: corn cob pellet and corn cob abrasive grits to use as blasting or finishing media. A comparative study has been performed with two products available on the market and with the same functions. The results show that cob-based products have lower impact than those currently used. The work provides indication for evaluating the benefits of turning agricultural wastes in natural-based materials and intends to promote circular economy processes in agriculture production.

Keywords: Life Cycle Assessment; maize waste; residue valorization; natural raw materials; biobased products

\section{Introduction}

In the European Action Plan, the Circular Economy has been defined as an economic system in which "the value of products, materials and resources is maintained in the economy for as long as possible, and the generation of waste minimised", while the Bioeconomy has been defined as "the production of renewable biological resources and the conversion of these resources and waste streams into value-added products, such as food, feed, bio-based products and bioenergy" [1]. The conversion of biological waste streams into value-added products, in the definition of the bioeconomy, represents an important principle of the circular economy itself and, consequently, for its realization and fulfillment. In bioeconomy, the general principle of the cascading use of biomass and waste streams provides the definition of priority actions and then secondary approaches [2-4]. Following this principle, the generation of the higher-value products such as food and animal feed should have the priority; then, it firstly should be considered the sustainable reuse/recycling of byproducts, wastes, and raw materials together with bioproduct manufacturing, and, finally, the implementation of energy-yielding technologies [5,6]. This approach following the cascading use principle is in agreement with the waste minimization concept defined as "a zero waste programme" [7] and can be considered as a crucial strategy for circular economy $[4,8,9]$. An ideal goal for any production sector is to modify its product chain, 
improving the efficiency, enabling reuse of all byproducts in the value chain, and reducing the waste production, trying to fulfill the zero waste criteria. The circular bioeconomy finds in agriculture one of the best sectors in which to play a key role in increasing the sustainability of the sector, given the countless possibilities of transforming crop residues and so recycling this precious biological resource [10].

In fact, agricultural waste- or agri-waste — can be considered the unwanted or unsalable materials deriving from agricultural processes. Similarly to food-waste, agri-waste can represent an environmental issue, but promoting their use and valorization, they can represent a benefit for several existing production processes. The implementation of these residues as novel raw material for production processes can promote the circularity and sustainability of these processes. In particular, crop wastes discarded directly on the field during harvesting are usually comprised of a cellulose backbone and, depending on their source, they may possess high carbon content and multi-functional groups. These properties have been researched upon the past and have led to employment of food and agri-waste in effluent management and biodiesel generation, as phytochemicals or catalysts [11,12]. Recently, agricultural waste management and its processes are considered more and more interesting topics for researchers [13]. Nevertheless, in common practice, agricultural waste is discharged to the surrounding environment without treatment or, in some situations, is burnt off, becoming an environmental loads. In this last scenario, the production of energy comes with the production of fly ash, which can nowadays be valorized in environmentally friendly methods. In fact, due to the high silica content, the fly ash can be considered a potential raw material for the synthesis of nanoporous materials, such as zeolites or mesoporous silica [14,15].

Agricultural wastes can be categorized in waste generated in the fields, after crop harvesting, (i.e., straw, stalk or leaves) [12] and waste generated after the crops are processed (i.e., husk, bagasse, peel or stover.) [16]. In the maize grain production process, the residues, such as corn stover-the above-ground portion of the plant including the cob remaining in the field after the grain harvesting-are very abundant, with an estimated residue yield of $8.9 \mathrm{t} / \mathrm{ha}$ with an averaged production of $85 \mathrm{Mt} /$ year, at the European level [17]. For example, the corn cobs represent about $20 \%$ by weight of standing residue and are buried or left in the field. In limited cases, they are collected during the harvesting and used as a biomass source for energy purposes, an alternative use having very limited economic value. Concerns associated with crop residue enhancement include an increase in nutrient removal from the field, and the potential for soil compaction due to additional field activities, an increase in the potential for wind and water erosion, and a potential reduction in soil organic matter [18]. As residue in the field, the cob could play a role in soil and water conservation and in soil nutrient dynamics since they provide surface cover and contain carbon and nutrients. However, Ref. [19] demonstrated that cob removal does not affect erosion or runoff and nutrient loss by rainfalls. Ref. [20] evaluated dry matter loss of buried cobs compared to the case of cobs placed on the soil surface, in three tillage systems, founding that the loss of dry matter was greater in the case of buried cobs. Nevertheless, effects on the nutrient dynamics, during the decomposition processes, are not sufficiently investigated, in the scientific literature. In [19], carbon and nutrient dynamics have been monitored, during the year after harvest, in the cases of cobs buried and laid on the surface. The decline in cob carbon content was due to the respiration losses, as soil microorganisms break down the residues [21]. In fact, while carbon content decreases as carbon compounds-used as energy sources by soil microorganisms-the nitrogen, phosphorous, and sulfur contents do not change, suggesting that little content of these elements is available for the crops during the first year of cob decomposition. In synthesis, harvesting cob results in a low nutrient removal rates. Then, corn cob can be considered an abundant and inexpensive biomass that can be removed from the field without deleterious effects, if a proper management is used. Considering the fact that corn cobs are a lignocellulosic material composed of cellulose, hemicellulose, and lignin, they can be turned into valuable raw materials to feed circular processes aimed at producing 
energy and bio-based products to be used in agricultural buildings and structures and more in general in the construction sector [22,23]. Moreover, potentially the cobs could be collected during the grain harvesting operations [24-26]. Further considerations should be made on the harvesting procedures and on the advancements needed to valorize the cob as a co-product. For example, Ref. [26] tested a single-pass combine equipped with an ear-snapper head able to collect $30 \%$ of the stover, where the higher percentage of mass is represented by cobs. In general, since the cob is more dense and less bulky than corn stalks and leaves, few additional operations should be required for harvesting, transporting, and storing. Finally, the decision to collect cob during harvesting would leave the more bulky material as stalks and leaves [27] on the soil for protection and improvement, preserving the current role of the residues on the field. The possible solutions, to use the cobs as co-product, are multiple and mainly related to energy production, organic biomass supply for farms or biogas production, feed preparation, and biotechnological production. In this case, the corn cobs are considered as raw material for the production of pellets, for energy purposes, and of inert grits, usable as blasting or finishing media, in the metalworking sector. To compare the different possibilities and select the most appropriate choice from the environmental sustainability point of view, the results of an analysis of the environmental impact assessment of the different alternatives can be used as selection criterion. Considering this aspect, Life Cycle Assessment (LCA) is one of the methodologies that can be applied to compare the benefits of different production processes with respect to others. Many researchers have reported the benefits of applying the LCA approach in terms of environmental management of agricultural production systems. Many studies have been conducted on the environmental impact assessment of maize production [28]. For example, Ref. [29] has assessed the environmental impact of wheat and maize production, in Italy, by means of the ILCD environmental impact assessment methodology developed by the European Commission. Moreover, Ref. [30] has evaluated the environmental impact of the cultivation of corn grain with the co-production of corn stover in the US Corn Belt and assessed the effects of corn stover removal in terms of both emissions and reduction of nitrogen availability in soil. Studies of the impact have been carried out on the utilization of biomass from agricultural residues, such as in [31], where the cost and energy requirements for the biomass pellet production have been evaluated in the Swedish scenario. Ref. [32] has assessed the environmental impact and the economic value of the corn straw pellet fuel in a Chinese province. The aim of this study is to consider and evaluate the environmental impact of two valorization scenarios corn cob through Life Cycle Assessment analysis: cob pellets $(\mathrm{CP})$ and abrasive cob grits (CG). These materials have been compared with an analogous product, with similar application and properties, currently available on the market (wood pellets (WP) and the silicon carbide inert (SC)). The work aims to provide useful information for the exploitation of corn cob as a co-product in the agricultural sector.

\section{Materials and Methods}

The LCA methodology is based on the International Standard ISO 14040 (Environmental management-Life cycle assessment-Principles and framework) and ISO 14044 (Environmental management-Life cycle assessment-Requirements and guidelines). The two documents explain the goal and define the scope, the functional unit, the system boundary choice, the life cycle inventory analysis preparation, and the impact assessment analysis [33,34]. The analysis is able to take into account different environmental impacts that are easy to overlook when the economical aspect prevails, such as energy consumption and atmospheric emissions, over the entire life cycle of a product or a service. Moreover, LCA can also consider a multitude of other environmental impacts on different compartments (i.e., air, water, soil, and human health). This methodology has proven to be useful to investigate and to highlight critical process phases and can be used as a decision tool for improving or optimizing production chain actions. In this study, an LCA analysis is applied firstly to two ideal valorization processes of corn cob, recovered from maize field. Then, the analogous LCA analysis has been conducted for the production processes of 
wood pellets and silicon carbide, in order to compare, respectively, the analogous products. The LCA investigates in detail the processes of the harvesting of corn cob, as a co-product in the field and not as a waste of maize grain production, and the subsequent use for the production of pellets and granulates, with a cradle to gate approach. The functional unit has been defined as $1 \mathrm{~kg}$ of final product of the four different materials (i.e., corn cob pellets, corn grits, wood pellets, and silicon carbide granulate). This functional unit has been chosen considering that all these products can be sold on the market, in both bulk and packs of different sizes according to the market segment. Primary data on maize grain cultivation have been collected from a case study farm. They consist of:

- details of cultivation processes (i.e., sowing, tillage, irrigation);

- $\quad$ working time of processes;

- fuel consumption of tractors and machinery;

- $\quad$ pesticides and fertilizers type, compositions, and consumption data;

- distances performed by machinery/tractors.

The secondary data from Ecoinvent 3.6 database [35] have been used as flows and process sources when primary data were not available. The analyses have been conducted through OpenLCA v1.10, an open source software for LCA analysis [36].

\subsection{System Boundaries and Scenarios}

The scope of the research includes the complete process of the products' life cycles from the raw material extraction, to the final products, ready to be marketed, as in the cradle-to-gate perspective. The system boundaries of the two different scenarios considered for corn cob valorization have been presented in Figure 1. The life cycle scenarios consider three phases:

1. raw materials production (corn cob);

2. transportation to the processing site;

3. processing of the raw materials for the production of the new product.

The raw materials are obtained from a background system, common to both Scenario 1 and Scenario 2, and aimed to provide as a main product the maize grains. The background system consists of cultivation, harvesting, and preparation of the maize grains and, in this background system, the corn cob has been considered a co-product. The collecting phase of the corn cob can be considered a phase of the cultivation process, carried out in parallel to the maize grain separation. Indeed, external machines implementable on the harvesters for the separate collection of grains and chopped cobs are available today. The two scenarios system considers the transportation to the processing factory and the commuting steps, as shown in Figure 1, obtaining the products ready to be sold. A transport distance of $100 \mathrm{~km}$ between the farm and the processing plant has been hypothesized in both scenarios, as representative average distance between the farm and processing plant (feed and organic litter production) in the area under study. The two scenarios have been analyzed in the hypothesis of considering a small-scale proximity production (i.e., a local scale system), which would make the exploitation of these residues advantageous [37]. The packaging phase is excluded from the boundary system defined for the investigation, considering the fact that the packaging type, size, and material are heterogeneous and depend on the factory policies and choices.

Concerning the comparative products, on one hand, the manufacture of silicon carbide consists of the reaction of silicon dioxide and carbon, yielding silicon carbide and carbon monoxide [38]. The system boundaries are included from the silica sand mining operation to the production of silicon carbide. The process also considers electricity consumption and transports, keeping constant the distances between production factory and raw materials extraction site, as previously defined from farm to factory. On the other hand, the production system of wood pellets considers wood residue from sawmills and woodchips as raw materials. In particular, the raw materials primarily are pre-treated and dried, then comminuted and mixed, then pelletized and cooled [39]. The database system also involves 
the packaging processes for the $20 \%$ of the total product, while the $80 \%$ of the product is considered to be sold unpacked. In this case, the system boundaries for the wood pellets neglecting this process consider the whole product sold unpacked.

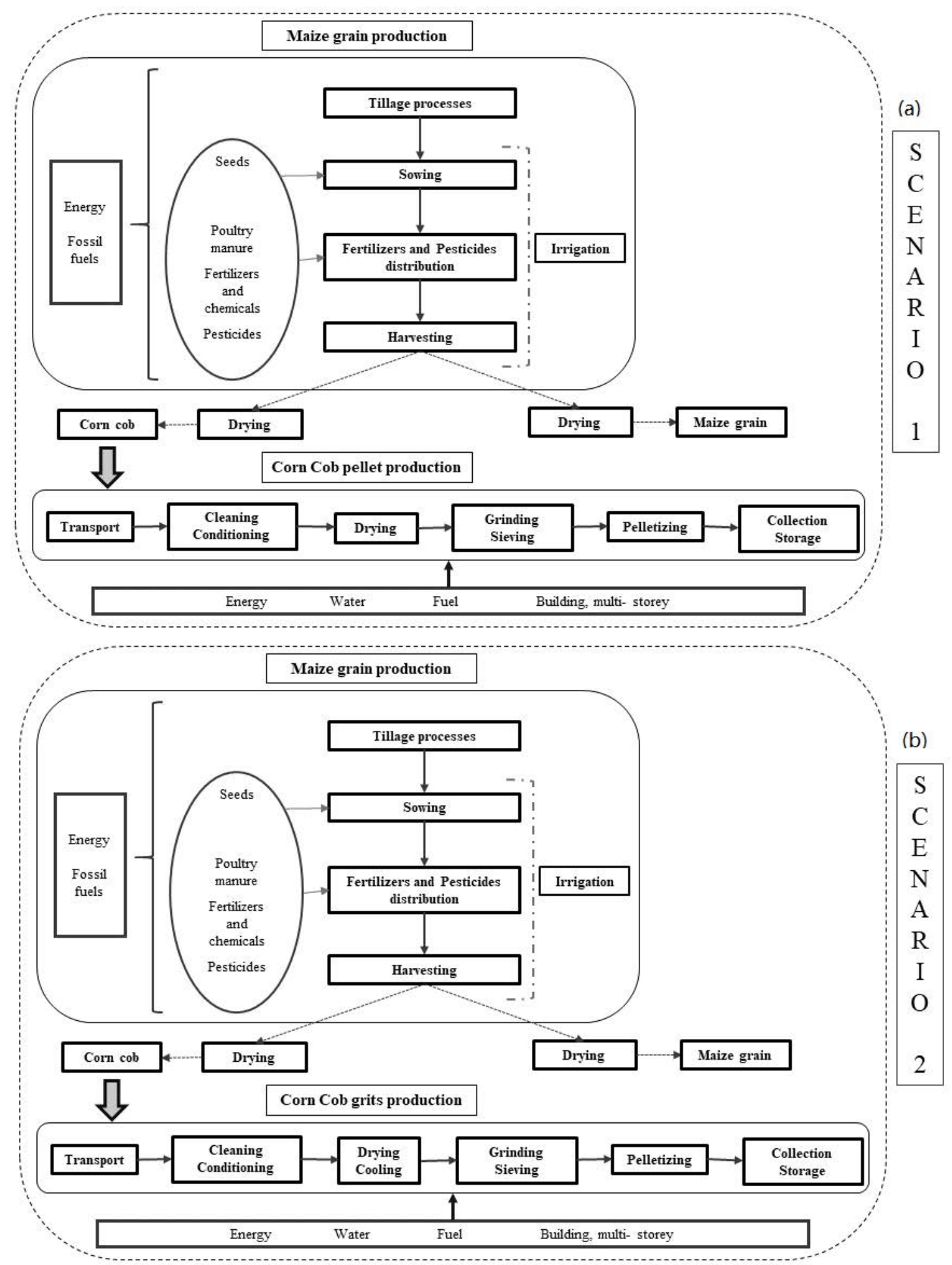

Figure 1. Boundaries of the two systems for the valorization of the corn cob: (a) Scenario 1 for the production of corn cob pellet; (b) Scenario 2 for the production of corn cob grits. 


\subsection{Focus Area}

The area considered in the work is in the North of Italy, the area with the highest national concentration of grain maize crops. In fact, in Italy, the four regions specialized in the production of grain maize are: Lombardy, Veneto, Piedmont, and Emilia-Romagna. The four regions concentrate about $87 \%$ of the Italian surface invested in maize cultivation (grain maize and waxy maize) [40]. Table 1 describes the extension of the Italian territories devoted to maize production, compared with the four above cited regions. The data refer to the last three years. They clearly show that the large percentage of Italian production of maize grain is located in these four regions. Furthermore, in these four regions, the farms involved in the maize cultivation are numerous (about 100,000) and generally have small extensions. Specifically, from the data of the Italian National Institute of Statistics (Istat) of the year 2016, the farms in these four regions were 79,081 units, for a total maize cultivated area of 592,546 hectares.

The Veneto Region, located in the northeast of Italy (see Figure 2), has the highest number of cultivated hectares between all the Italian Regions, with a surface dedicated to corn crop equal to 165,352 in 2017. In particular, the distribution between the provinces of the Veneto Region highlights Padua as the province with the highest surface dedicated to maize crops and highest production, as reported in Table 2.

These data have been used for the selection of the case study area, as shown in Figure 2. In particular, primary data for the crop cultivation have been collected in a study case farm in the Padua Province, being the area with the highest number of cultivated hectares with maize grain. Analogously, the processes also related to the valorization of the corn cob have been located in the North of Italy, as well as the processes for the pellet wood production and the silicon carbide production.

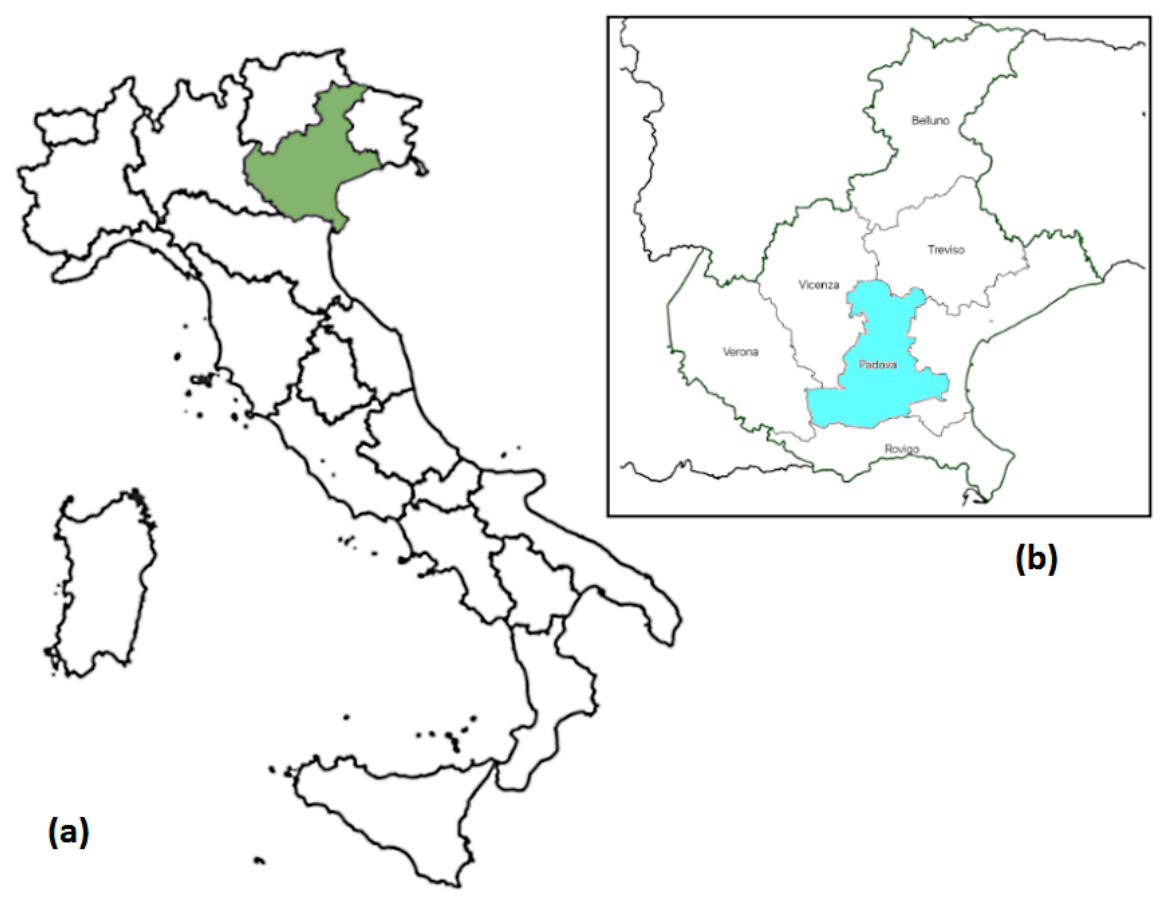

Figure 2. Geographical position of the area investigated in the study. (a) Italian territory with the Veneto region highlighted in green; (b) focus on the provinces of the Veneto Region, with Padua (Padova in Italian) pointed out in light blue. 
Table 1. Area dedicated to maize cultivation in hectares (ha): (a) Northern Italy (Lombardy, Veneto, Piedmont, Emilia-Romagna, (b) Italy.

(a)

\begin{tabular}{cccccc}
\hline Year & Total & Waxy & $\mathbf{( \% )}$ & Grain & (\%) \\
\hline 2017 & 573,407 & 277,909 & 48.47 & 295,498 & 51.53 \\
2018 & 518,524 & 287,482 & 55.44 & 230,942 & 44.53 \\
2019 & 556,782 & 299,663 & 53.82 & 257,119 & 46.18 \\
\hline \multicolumn{7}{r}{ (b) } & & \\
\hline Year & Total & Waxy & $\mathbf{( \% )}$ & Grain & $\mathbf{( \% )}$ \\
\hline 2017 & 645,261 & 342,101 & 53.02 & 303,160 & 46.98 \\
2018 & 591,206 & 355,527 & 60.1 & 235,879 & 39.9 \\
2019 & 628,801 & 367,422 & 58.43 & 261,379 & 41.57 \\
\hline
\end{tabular}

Table 2. Data of maize production ( $t$ ) and dedicated surfaces (ha) of the Provinces of the Veneto Region.

\begin{tabular}{lcc}
\hline Provinces & Dedicated Surfaces (ha) & Annual Production (t) \\
\hline Belluno & 1522 & 1100.89 \\
Padua & 36,356 & $30,992.9$ \\
Rovigo & 34,568 & $30,449.8$ \\
Treviso & 21,867 & $21,126.8$ \\
Venice & 30,702 & 30,314 \\
Verona & 25,790 & $22,532.5$ \\
Vicenza & 14,547 & $12,996.55$ \\
\hline
\end{tabular}

\subsection{Life Cycle Inventory (LCI)}

The life cycle inventory analysis is the process of data collection and analysis aiming at quantifying the resource inputs, the energy consumption, and the environmental outputs to take into account in the life cycle of a product $[41,42]$. Primary data include detailed information on the maize cultivation and are based on the interviews with the farmers. Primary data related to corn cob production were not available for the study and therefore have been calculated from maize grain production, considering literature parameters. In fact, the corn cob production quantities have been obtained for the areas under consideration starting from the data on maize grain production. Average data on maize grain and corn cob productions ( $\mathrm{t} / \mathrm{ha}$ ), referred to the geographical area of the Northern Italy, have been extracted from [43] and summarized in Table 3.

Since the cob, on average, represents $15 \%$ of the weight of an ear corn when harvested, in the hypothesis of a grain production about $15 \mathrm{t} / \mathrm{ha}$, a potential harvest of $3 \mathrm{t} / \mathrm{ha}$ of $\operatorname{cob}(42 \%$ humidity) is expected, with a ratio between the two products (based on the dry matter) of 11.6 [43]. In this study, the maize grain production have been estimated by primary data of $14.2 \mathrm{t} / \mathrm{ha}$. Literature data are available for the production of maize corn cobs based on dry matter values, as visible in Table 3 . 
Table 3. Data on maize grain and maize corn cob productions.

\begin{tabular}{lccc}
\hline Literature Data & $\begin{array}{c}\text { Average } \\
(\mathbf{t} / \mathbf{h a})\end{array}$ & $\begin{array}{c}\text { Minimum } \\
(\mathbf{t} / \mathbf{h a})\end{array}$ & $\begin{array}{c}\text { Maximum } \\
\text { (t/ha) }\end{array}$ \\
\hline Maize grain production (14\% of humidity) & 15.1 & 7.8 & 19.1 \\
\hline Maize Corn Cob production (42\% of humidity) & 3.0 & 1.8 & 4.1 \\
\hline Maize Corn Cob production (dry matter-14\% of humidity) & 1.9 & 1.3 & 2.4 \\
\hline Ratio (corn cob/maize grain) & 18.7 & 12.2 & 35.2 \\
\hline Ratio (dry corn cob/maize grain (14\% of humidity)) & 11.6 & 6.7 & 25.6 \\
\hline
\end{tabular}

Data on water consumption for irrigation have been assumed from literature, based on rain precipitation data. The impoverishment of soil nutrients due to the lack in the field of the corn cob, even limited, has been taken into account, on the basis of literature data. In the study [19], this impoverishment has been modeled and quantified, in order to be considered in the LCA analysis, in grain and the cob corn production phase as avoided emissions to soil (see Table 4).

Table 4. Data of avoided emissions by cobs removal from field, based on the production of one ton of corn cobs.

\begin{tabular}{cc}
\hline Emission to Soil & Amount (kg) \\
\hline Carbon & -453 \\
\hline Copper & -0.0033 \\
\hline Iron & -0.19 \\
\hline Magnesium & -0.008 \\
\hline Nitrogen & -3.7 \\
\hline Phosphorous & -0.3 \\
\hline Potassium & -11.5 \\
\hline
\end{tabular}

Life cycle inventory data, input and output, for the production of corn cob pellets and corn cob grits have been obtained from the literature. Finally, for the production of wood pellets and silicon carbide, the processes available in the database Ecoinvent 3.6 have been considered. For the modeling of flows and processes, the software OpenLCA 1.10.2 has been used.

\subsection{Allocation}

Allocation procedure is defined in the ISO 14041 (Environmental management-Life cycle assessment-Goal and scope definition and inventory analysis) as partitioning the input and/or output flows of a process to the product systems under study. In order to evaluate the environmental performance of the cob-based products, the allocation between grains and cobs represents a necessary step. The ISO 14044 [44] recommends to avoid allocation, whenever possible. However, if not avoidable, the ISO series recommends to use methods that reflect the physical relationships—such as mass or energy content-or other relevant variables, e.g., the economic value of the products [45]. In this study, the corn cobs have been assumed to be a co-product of the main production-the maize grains-and the physical allocation approach based on the mass values has been adopted. Starting from the data collected on the case study farm, the mass percentages of grains and cobs, with respect to the total production mass, have been calculated. The mass ratio between grains and cobs residues is about 8:1 with a cob production about one ton every eight tons of grains production (dry matter at $14 \%$ of humidity). Therefore, the allocation percentages used for the cultivation processes have been $88 \%$ and $12 \%$ for grains and cobs, respectively. 


\subsection{Environmental Impact Assessment}

In order to quantify the environmental impact of the LCI adopted in the study, the life cycle impact assessment (LCIA) has been adopted. The impact assessment process is made of three main phases: (i) characterization, (ii) normalization, and (iii) weighting. The first step concerns the classification of the emissions into impact categories and their characterization in common units, allowing a direct comparison. In this study, the impact assessment has been performed following the methodology proposed by the Joint Research Center, Institute for Environment and Sustainability (JRC-IES), in accordance with the International Reference Life Cycle Data system (ILCD). In the ILCD guidance document [46], a detailed description of models, methods, and methodological choices is provided. The JCR-IES recommendations are based on existing models evaluated in the general framework of the three conventional areas of human health, natural environment, and natural resources ([37]), and suggest the following impact categories: Acidification; Climate change (100 year horizon); Freshwater (ecotoxicity and eutrophication); Human toxicity (carcinogenics and non-carcinogenics); Ionizing radiation (ecosystems and human health); Land use; Marine eutrophication; Ozone depletion; Particulate matter/Respiratory inorganics; Photochemical ozone formation; Mineral, fossils and renewables resource depletion; Water resource depletion; and Terrestrial eutrophication.

This work has given relevance to nine impact categories in particular, from the ILCD 2011 Midpoint+ methodology, based on their characteristics:

- global warming: 100-year time horizon global warming potentials [47] are used for the assessment of climate change category. It is measured in terms of $\mathrm{CO}_{2}$ equivalent indicator and referred to greenhouse gas emissions throughout the study;

- land use: impact category reflects the damage to ecosystems due to the effects of occupation and transformation of land;

- minerals, fossils, and renewable resource depletion: impact category considers variation on their availability;

- water resource depletion: category addressing the use of water in relation to the scarcity of this fundamental and primary resource;

- acidification: category addressing the impacts generated by the emission of airborne acidifying chemicals. It refers literally to processes that increase the acidity of water and soil systems by hydrogen ion concentration. It is caused by atmospheric deposition of acidifying substances generated largely from emissions of nitrogen oxides $\left(\mathrm{NO}_{\mathrm{x}}\right)$, sulphur dioxide $\left(\mathrm{SO}_{2}\right)$, and ammonia $\left(\mathrm{NH}_{3}\right)$, the latter contributing to acidification after its nitrification in the soil;

- human toxicity: category based on models that account for particular chemical compounds in the environment, human exposure, and differences in toxicological response;

- ecotoxicity and eutrophication of freshwater: two categories addressing the impacts not only from the macro-nutrients, nitrogen and phosphorus, in bio-available forms on aquatic and terrestrial ecosystems, but also, similarly to human toxicity, from chemical compounds in the environment, species exposure, and differences in toxicological response;

- terrestrial eutrophication: category addressing the excess atmospheric nitrogen deposition causing damages on ecosystems and biodiversity.

In addition, the energy consumption of the investigated processes has been analyzed and considered based on the Cumulative Energy Demand (CED) methodology. The method is suited to determine and compare the energy intensity of different processes [48,49].

\section{Results}

In Figure 3, the results of the nine indicators for both the corn cob grit and corn cob pellet and other products are presented. The two materials show similar indicators in all the evaluated categories, with constantly higher values for the processes for the pellet preparation. The more evident differences are referred to freshwater eutrophication and the mineral, fossil, and renewable resource depletion impacts, with corn pellets providing impact values, respectively $49 \%$ and $40 \%$ higher than corn grits. Overall, the production 
process of cob grits has lower impact (about $27 \%$ ) than cob pellets. The impact results of cob-based materials, CP and CG, have been compared with WP and SC respectively, as shown in Figure 3. The cob grits demonstrate to have less impact, on all the indicators, if compared to the silicon carbide abrasive inert. In particular, the corn cob grits production presents a land use indicator of $0.186 \mathrm{~kg} C$ deficit compared to $9.913 \mathrm{~kg} C$ deficit of the silicon carbide, as visible in Table 5. Considerable differences can also be observed for freshwater euthrophication, human toxicity, acidification, terrestrial eutrophication, and water resource depletion. Another important result is that climate change impact of the corn cob grits resulted in being negative, and equal to $-0.882 \mathrm{~kg} \mathrm{CO}_{2}$ eq, significantly lower than silicon carbide value, equal to $6.071 \mathrm{~kg} \mathrm{CO}_{2}$ eq.
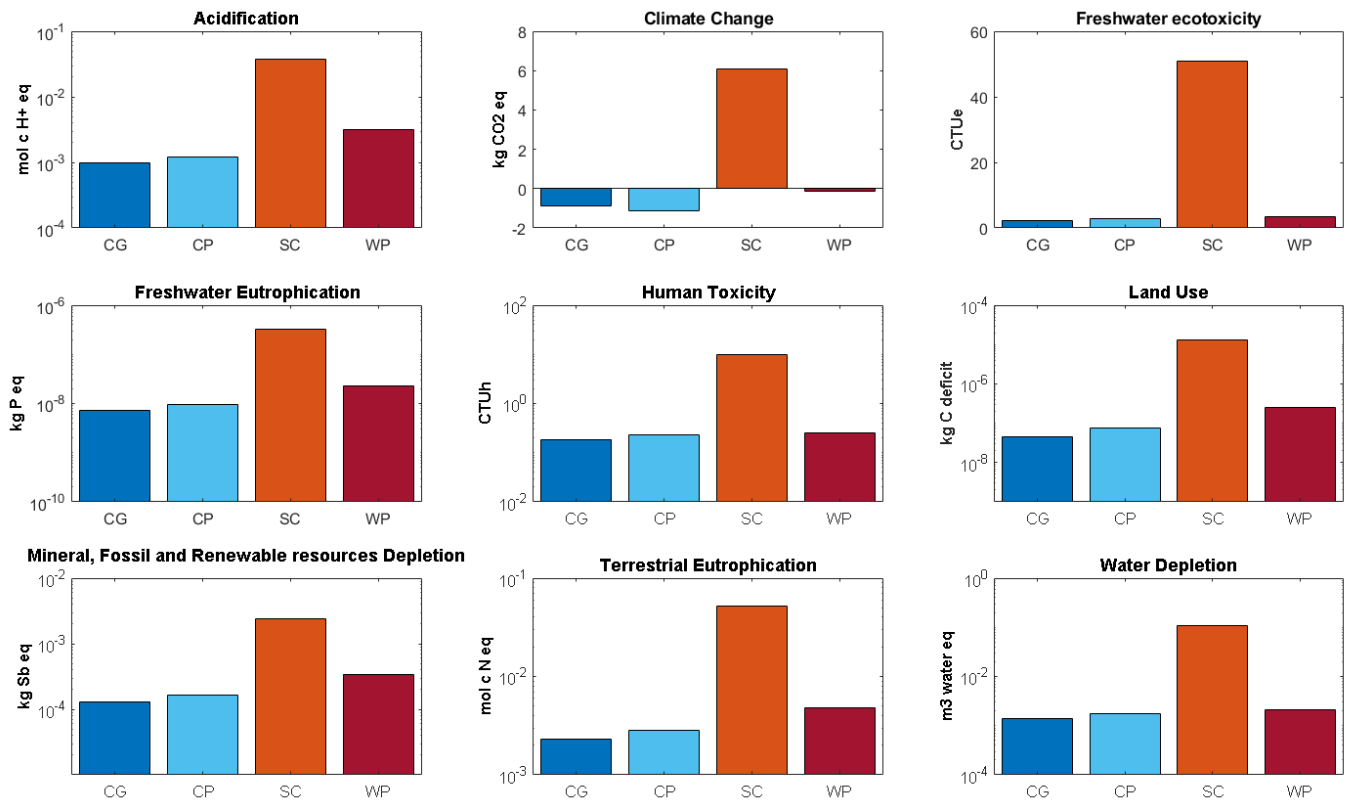

Figure 3. Presentation of the results of the impact analysis based on the nine selected impact voices, comparing corn cob grits (CG) and pellet (CP) with silicon carbide (SC) and wood pellet (WP): CG results are blue, $\mathrm{CP}$ results are light blue, $\mathrm{SC}$ results are orange, and WP results are red.

Table 5. Impact analysis results based on ILCD2011+ impact categories.

\begin{tabular}{lcccc}
\hline Categories & Corn Cob Grits & Silicon Carbide & Corn Cob Pellet & Wood Pellet \\
\hline Acidification (molc H+ eq) & 0.001 & 0.037 & 0.001 & 0.003 \\
Climate change (kg CO 2 eq) & -0.882 & 6.071 & -1.147 & -0.1585 \\
Freshwater ecotoxicity (CTUe) & 2.101 & 51.024 & 2.895 & 3.2765 \\
Freshwater eutrophication (kg P eq) & $6.63 \times 10^{-6}$ & 0.004 & $1.35 \times 10^{-5}$ & 0.0002 \\
Human toxicity(CTUh) & $7.20 \times 10^{-9}$ & $3.27 \times 10^{-7}$ & $9.6 \times 10^{-9}$ & $2.15 \times 10^{-8}$ \\
Land use (kg C deficit) & 0.186 & 9.913 & 0.233 & 0.314 \\
Resources depletion (kg Sb eq) & $4.53 \times 10^{-8}$ & $1.31 \times 10^{-5}$ & $7.71 \times 10^{-8}$ & $2.52 \times 10^{-7}$ \\
Terrestrial eutrophication (molc N eq) & 0.002 & 0.052 & 0.003 & 0.005 \\
Water depletion (m ( $^{3}$ water eq) & 0.001 & 0.11 & 0.002 & 0.002 \\
\hline
\end{tabular}

Analogous results, favorable to the corn cob product, can be also observed in the other application, where the two different kinds of pellets are analyzed. In this case, the cob pellet has significantly better results than wood pellet, in terms of freshwater eutrophication, mineral and other resources depletion and, most importantly, climate change. In fact, the climate change impacts are both negative, showing that they are virtuous processes in terms of equivalent carbon dioxide emitted. However, the carbon footprint of the cob pellet is around eight times lower than the wood pellet. A further parameter of interest for the 
scope of the research could be the evaluation of the energy demand during the production phase. The energy demand results, visible in Figure 4, exhibit trends similar to the other impact categories. In fact, the silicon carbide shows an energy demand considerably higher, 139.4 MJ, than other products. The cob products and the wood pellet have analogous demand. However, the cob grits process has an energy demand $22 \%$ lower than the cob pellet process, which has, in turn, $18 \%$ higher impact than the wood pellet. Globally, the cob grits show the lowest impact among the four investigated products. Then, in order to identify the most impacting components on the final assessment, for each product, the various contributions should be analyzed in deeper detail. In Figures 5-8, the different contributions to the final indicators for climate change, human and water toxicity, and water depletion are respectively shown. The different contributions have been grouped in seven macro-items: raw materials, transport, electricity, heat production, building facilities, fossil fuel, and other processes. The last item incorporates the marginal contributions, lower than $1 \%$, to the impact category. As far as the climate change indicator is concerned, the raw materials preparation has the highest contribution in cob products and wood pellets. They have a positive contribution in the processes and are responsible for the negative value of this midpoint indicator. On the contrary, for the silicon carbide production, the raw materials have a marginal contribution. Another consistent contribution is the electricity consumption that proved to be relevant in all four cases. The electricity consumption covers $58 \%$ of the climate change impact of the silicon carbide production. On the contrary, for the other products, it exhibits a limited impact. It can be noticed that the cob grits has a slightly higher electricity consumption compared to the cob pellet. Transportation has a small but visible impact on the cob process. On the contrary, it has a more noticeable contribution in the other two production processes. This assertion can be assumed analyzing the fossil fuel category that, for the reference products, groups all the processes/actions involving fossil fuel consumption. In fact, considering the low amount of fuel used for machine operation during the processing phase of WP and SC, fossil fuels consumption is mainly attributable to the transportation processes. Waste disposal and heat production are two specific contributions of silicon carbide and wood pellet processes, respectively. The first has a marginal participation $(1 \%)$ on this impact category; on the contrary, the heat production has a remarkable role (35\%) on the climate change indicator. Moreover, in case (c) in Figure 5, several smaller contributions, grouped under "Others", impact for the 33\% on the total $\mathrm{kg} \mathrm{CO}_{2}$ eq. The contributions in the water ecotoxicity impacts, in Figure 6, are similar for the two cob based materials. However, compared to Figure 5, the building facilities' contributions have the highest percentages, $48 \%$ for the cob grits and $43 \%$ for the cob pellet. These contributions involve construction and maintenance of the facilities considered in the models. The same contribution is present in the wood pellet production for $16 \%$. Similar magnitudes characterize the raw materials' voice. The main contribution (equal to $92 \%$ ) of the silicon carbide process is due to electricity consumption and the others can be considered marginal, since their percentages are lower than $4 \%$. Transportation has the same contributions to both cob valorization processes, circa 5\%. Differently, the electricity consumption has a higher contribution (14\%) in cob pellet production compared to cob grits production $(7 \%)$. The electricity consumption has a similar magnitude on the wood pellet production. In the water ecotoxicity assessment, the contributions of waste disposal and heat production, in silicon carbide production and wood pellet production respectively, are analogous to the climate change assessment. The results related to the contributions in the water ecotoxicity impact, shown in Figure 6, are analogous in terms of magnitudes to the human toxicity assessment. Differently, the water depletion impact is characterized by similar magnitude contributions for cases (a) and (b), with more than $90 \%$ attributed to raw material preparation and supply and energy consumption. The contributions of transportation and other processes are negligible. An important role of raw materials is noted in case (d) where the main impact is due to the electricity consumption $(57 \%)$. The heat production has the third highest contribution (14\% of the total impact). 
In the silicon carbide case, the electricity consumption is responsible for almost the total water depletion impact with the $96 \%$; other contributions are negligible.

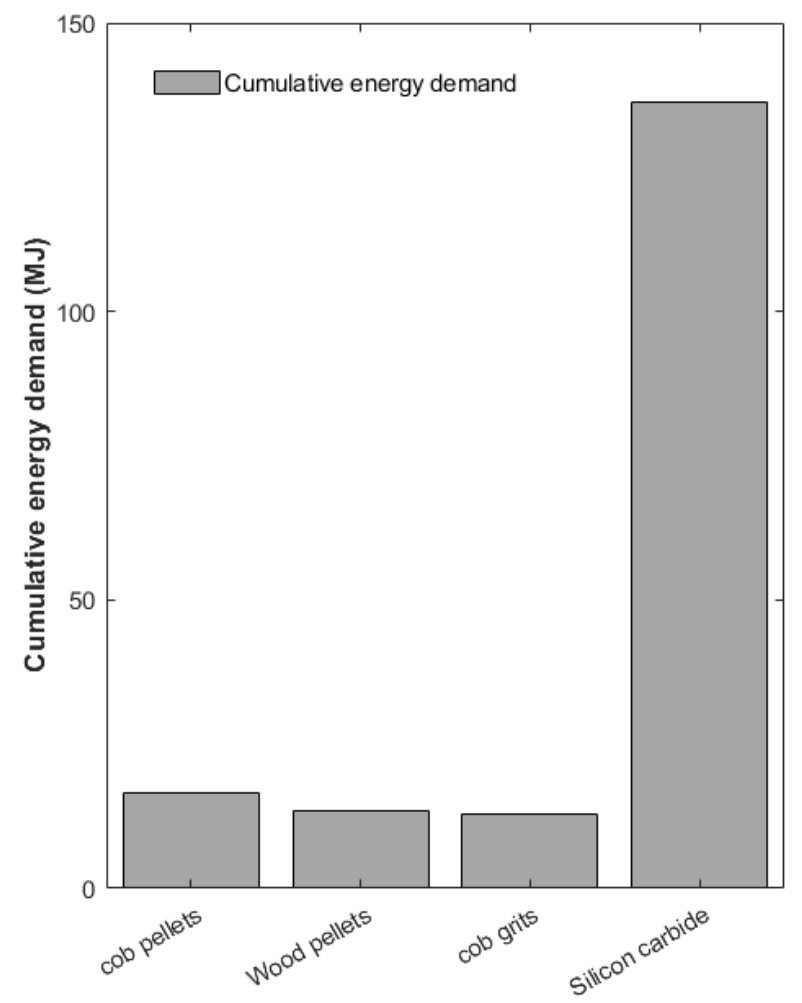

Figure 4. Total energy demand of the four products under study.

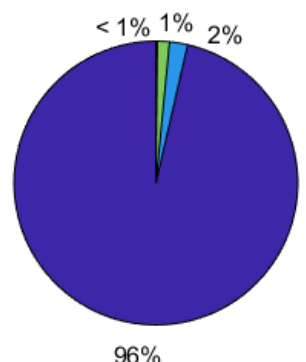

$96 \%$

(a) Cob grits

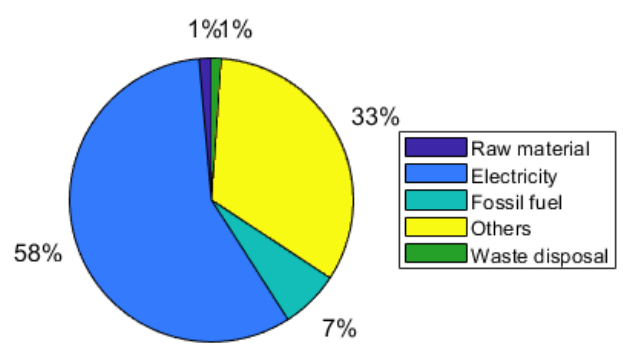

(c) Silicon carbide
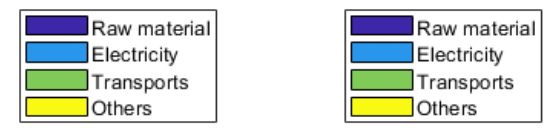

Oothers

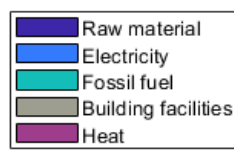

Heat

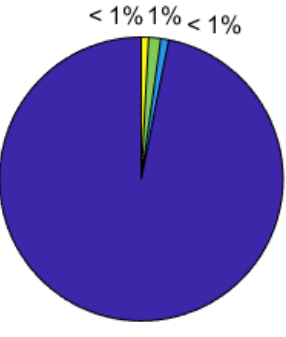

$97 \%$

(b) Cob pellet

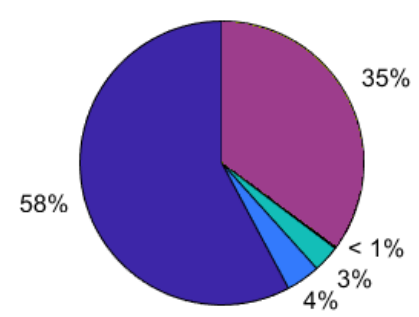

(d) Wood pellet

Figure 5. Contributions to the climate change impacts for the four different production processes: (a) cob grits; (b) cob pellet, (c) silicon carbide and (d) wood pellets. 


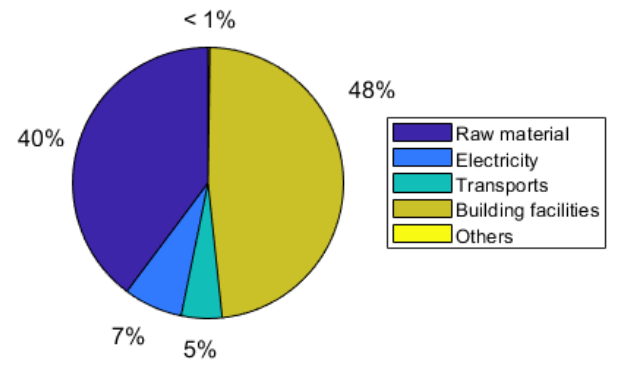

(a) Cob grits

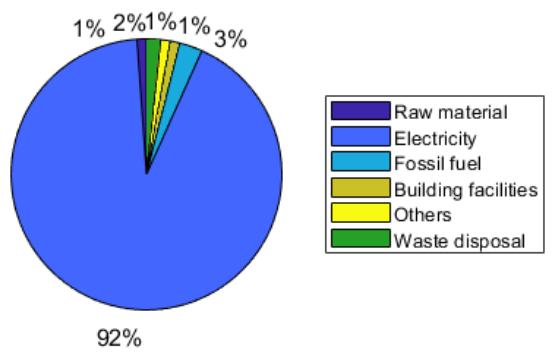

(c) Silicon carbide

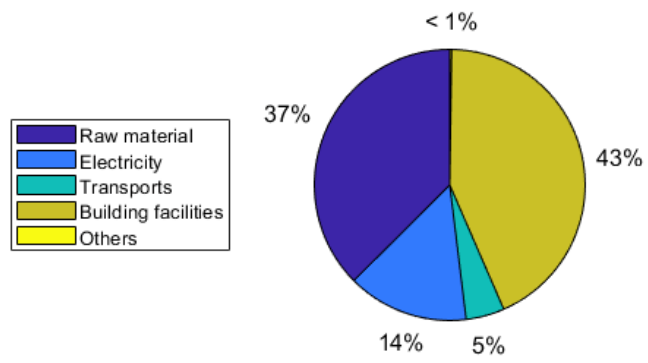

(b) Cob pellet

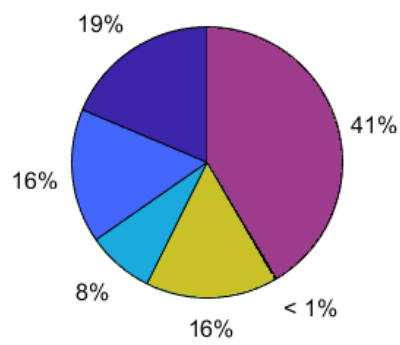

(d) Wood pellet

Figure 6. Contributions to the water ecotoxicity impacts for the four different production processes: (a) cob grits; (b) cob pellets; (c) silicon carbide; and (d) wood pellets.

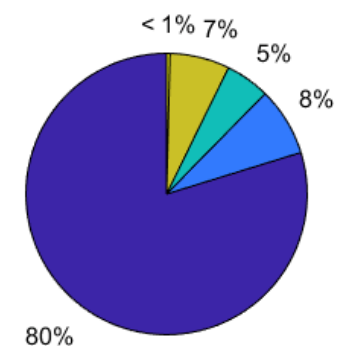

(a) Cob grits

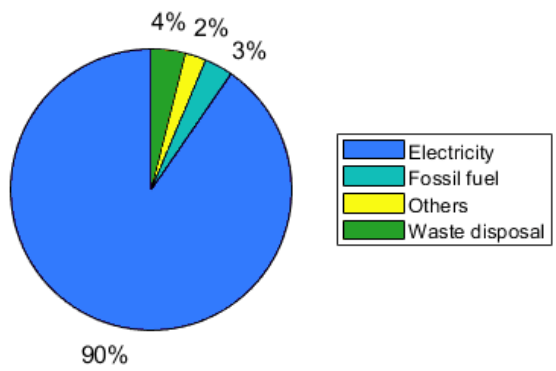

(c) Silicon carbide

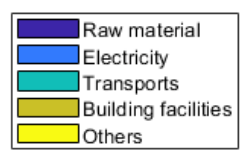

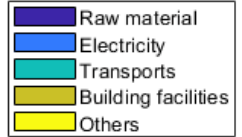

Others

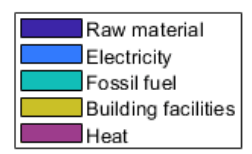

Figure 7. Contributions to the human toxicity impacts for the four different production processes: (a) cob grits; (b) cob pellets; (c) silicon carbide; and (d) wood pellets.

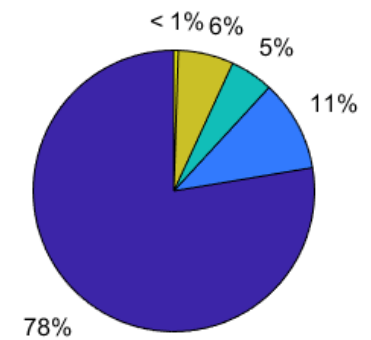

(b) Cob pellet

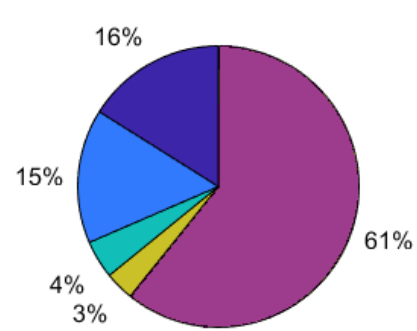

(d) Wood pellet 


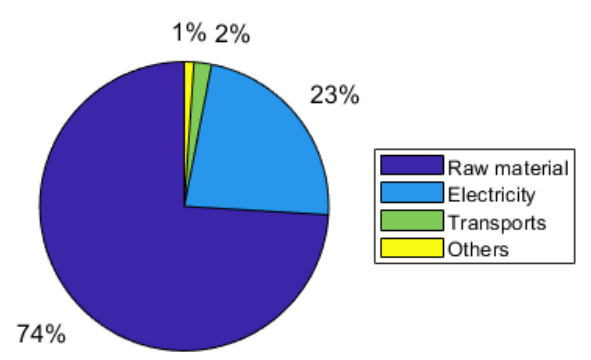

(a) Cob grits

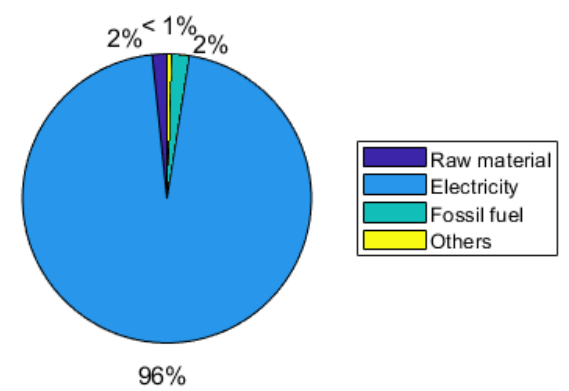

(c) Silicon carbide

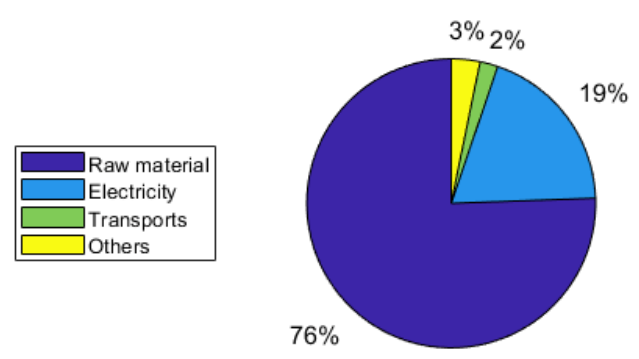

(b) Cob pellet

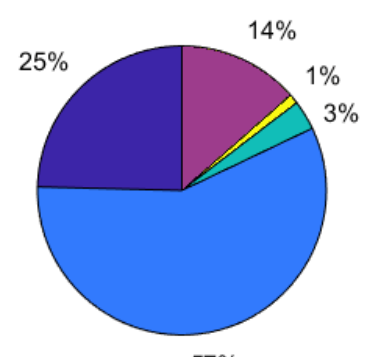

(d) Wood pellet

Figure 8. Contributions to the water depletion impacts for the four different production processes: (a) cob grits; (b) cob pellets; (c) silicon carbide; and (d) wood pellets.

\section{Conclusions}

This study provides a reliable assessment of the environmental performance of the corn cob valorization as raw material for pellet and grits production in a Northern Italy context. Moreover, the comparison with similar products available on the market has proved that this agricultural residue could be an interesting and valuable raw material for different applications. In fact, cob pellet and cob grits, used as alternative materials, have provided a lower environmental impact, based on the categories under study, than wood pellet and silicate carbide grits, respectively. However, the cob pellet has shown slightly higher energy consumption compared to the corresponding product on the market. On the contrary, the cob grits scenario has presented globally a reduced environmental impact on the four products basis. The negative aspect concerns the seasonality of the maize crop, which makes the cobs a raw material not available throughout the year. Furthermore, despite the high amount of lignite, corn cob is difficult to store during the year because it risks rotting. Considering these aspects, further analysis could involve the use of corn cob as part of a mixed product, substituting part of the fresh raw material currently in use. Moreover, further development of the work would consider the collection and the implementation of reliable primary data for the different phases of the production processes for all the materials considered in the study. This will allow for having a more robust comparison between different materials and different applications. However, the Life Cycle Assessment analyses, conducted in this study, are a useful preliminary investigation of the impact of these enhancement processes and could be helpful as decision-making information, converting the corn cob into the status of co-product and therefore driving investments accordingly. Both valorization processes have been evaluated on the basis of environmental impacts providing positive and interesting feedback. Despite this, the feasibility of the investments necessary for the in field collection of this residue, and, consequently, the economic return for farmers, must be better investigated in future works. 
Author Contributions: Conceptualization, E.S., M.B., A.B.; methodology, E.S., M.B., A.B.; software, E.S.; validation, M.B., A.B.; formal analysis, E.S.; investigation, E.S., M.B., A.B., D.T.; resources, D.T.; data curation, E.S.; writing—original draft preparation, E.S., M.B., A.B.; writing-review and editing, D.T. and P.T.; visualization, E.S., M.B., A.B.; supervision, P.T.; project administration, D.T.; funding acquisition, P.T. All authors have read and agreed to the published version of the manuscript.

Funding: This research received no external funding.

Institutional Review Board Statement: Not applicable.

Informed Consent Statement: Not applicable.

Conflicts of Interest: The authors declare no conflict of interest.

\section{References}

1. Directorate-General for Research and Innovation, European Commission. Review of the 2012 European Bioeconomy Strategy; Publications Office of the EU: Brussels, Belgium, 201 . [CrossRef]

2. OECD International Futures Programme. The Bioeconomy to 2030: Designing a Policy Agenda; Technical Report; OECD Publishing: Paris, France, 2006.

3. Diakosavvas, D.; Frezal, C. Bio-Economy and the Sustainability of the Agriculture and Food System: Opportunities and Policy Challenges; OECD Food, Agriculture and Fisheries Papers, No. 136; OECD Publishing: Paris, France, 2019; pp. 1-55. [CrossRef]

4. Kaszycki, P.; Głodniok, M.; Petryszak, P. Towards a bio-based circular economy in organic waste management and wastewater treatment-The Polish perspective. New Biotechnol. 2021, 61, 80-89. [CrossRef]

5. Lovarelli, D.; Bacenetti, J. Seedbed preparation for arable crops: Environmental impact of alternative mechanical solutions. Soil Tillage Res. 2017, 174, 156-168. [CrossRef]

6. Bacenetti, J.; Lovarelli, D.; Facchinetti, D.; Pessina, D. An environmental comparison of techniques to reduce pollutants emissions related to agricultural tractors. Biosyst. Eng. 2018, 171, 30-40. [CrossRef]

7. European Commission. Communication from the Commission to the European Parliament, the Council, the European Economic and Social Committee and the Committee of the Regions towards a Circular Economy: A Zero Waste Programme for Europe; Publications Office of the EU: Brussels, Belgium, 2014.

8. European Commission. First Circular Economy Action Plan; Publications Office of the EU: Brussels, Belgium, 2019.

9. Ubando, A.T.; Felix, C.B.; Chen, W.H. Bioresource Technology Biore fi neries in circular bioeconomy: A comprehensive review. Bioresour. Technol. J. 2020, 299. [CrossRef]

10. Abbas, F.; Hammad, H.M.; Anwar, F.; Farooque, A.A.; Jawad, R. Transforming a Valuable Bioresource to Biochar, Its Environmental Importance, and Potential Applications in Boosting Circular Bioeconomy While Promoting Sustainable Agriculture. Sustainability 2021, 13, 2599. [CrossRef]

11. Rao, P.; Rathod, V. Valorization of Food and Agricultural Waste: A Step towards Greener Future. Chem. Rec. 2019, 19, 1858-1871. [CrossRef]

12. Yahya, A.M.; Al-qodah, Z.; Ngah, C.W.Z. Agricultural bio-waste materials as potential sustainable precursors used for activated carbon production: A review. Renew. Sustain. Energy Rev. 2015, 46, 218-235. [CrossRef]

13. Mostafa, N.; Farag, A.A.; Abo-dief, H.M.; Tayeb, A.M. Production of biodegradable plastic from agricultural wastes. Arab. J. Chem. 2018, 11, 546-553. [CrossRef]

14. Miricioiu, M.G.; Niculescu, V.C. Fly Ash, from Recycling to Potential Raw Material for Mesoporous Silica Synthesis. Nanomaterials 2020, 10, 474. [CrossRef] [PubMed]

15. Miricioiu, M.G.; Niculescu, V.C.; Filote, C.; Raboaca, M.S.; Nechifor, G. Coal Fly Ash Derived Silica Nanomaterial for MMMsApplication in $\mathrm{CO}_{2} / \mathrm{CH}_{4}$ Separation. Membranes 2021, 11, 78. [CrossRef]

16. Caicedo, M.; Barros, J.; Ordás, B. Redefining Agricultural Residues as Bioenergy Feedstocks. Materials 2016, 9, 635. [CrossRef] [PubMed]

17. García-Condado, S.; López-Lozano, R.; Panarello, L.; Cerrani, I.; Nisini, L.; Zucchini, A.; Van der Velde, M.; Baruth, B. Assessing lignocellulosic biomass production from crop residues in the European Union: Modelling, analysis of the current scenario and drivers of interannual variability. GCB Bioenergy 2019, 11, 809-831. [CrossRef]

18. Wienhold, B.J.; Varvel, G.E.; Jin, V.L. Corn Cob Residue Carbon and Nutrient Dynamics during Decompositionduring Decomposition. Agron. J. 2008, 103, 1192-1197. [CrossRef]

19. Wienhold, B.J.; Gilley, J.E. Cob Removal Effect on Sediment and Runoff Nutrient Loss from a Silt Loam Soil. Agron. J. 2010, 102, 1448-1452. [CrossRef]

20. Burgess, M.; Mehuys, G.; Madramootoo, C. Decomposition of grain-corn residues (Zea mays L.): A litterbag study under three tillage systems. Can. J. Soil Sci. 2002, 82, 127-138. [CrossRef]

21. Johnson, J.M.F.; Barbour, N.W.; Weyers, S.L. Chemical composition of crop biomass impacts its decomposition. Soil Sci. Soc. Am. J. 2007, 71, 155-162. [CrossRef]

22. Barreca, F.; Fichera, C. Wall panels of Arundo donax L. for environmentally sustainable agriculture buildings: Thermal performance evaluation. J. Food Agric. Environ. 2013, 11, 1353-1357. 
23. Barreca, F.; Cardinali, G.; Fichera, C.; Praticò, P. Utilization of cork residues for high performance walls in green buildings. Agric. Eng. Int. CIGR J. 2018, 20, 47-55.

24. Varvel, G.E.; Wilhelm, W.W. Cob Biomass Production in the Western Corn Belt. Bioenergy Res. 2008, 1, 223-228. [CrossRef]

25. Hoskinson, R.L.; Karlen, D.L.; Birrell, S.J.; Radtke, C.W.; Wilhelm, W.W. Engineering, nutrient removal, and feedstock conversion evaluations of four corn stover harvest scenarios. Biomass Bioenergy 2007, 31, 126-136. [CrossRef]

26. Shinners, K.J.; Adsit, G.S.; Binversie, B.N.; Digman, M.F.; Muck, R.E.; Weimer, P.J. Single-pass, split-stream harvest of corn grain and stover. Trans. ASABE 2007, 50, 355-363. [CrossRef]

27. Pordesimo, L.O.; Edens, W.C.; Sokhansanj, S. Distribution of Above Ground Biomass in Corn Stover; American Society of Agricultural and Biological Engineers: St. Joseph, MI, USA, 2002. [CrossRef]

28. Supasri, T.; Itsubo, N.; Gheewala, S.H.; Sampattagul, S. Life cycle assessment of maize cultivation and biomass utilization in northern Thailand. Sci. Rep. 2020, 10,1-13. [CrossRef]

29. Fantin, V.; Righi, S.; Rondini, I.; Masoni, P. Environmental assessment of wheat and maize production in an Italian farmers' cooperative. J. Clean. Prod. 2017, 140, 631-643. [CrossRef]

30. Kim, S.; Dale, B.E.; Jenkins, R. Life cycle assessment of corn grain and corn stover in the United States. Int. J. Life Cycle Assess. 2009, 14, 160-174. [CrossRef]

31. Nilsson, D.; Bernesson, S.; Hansson, P.A. Pellet production from agricultural raw materials-A systems study. Biomass Bioenergy 2011, 35, 679-689. [CrossRef]

32. Song, S.; Liu, P.; Xu, J.; Chong, C.; Huang, X.; Ma, L.; Li, Z.; Ni, W. Life cycle assessment and economic evaluation of pellet fuel from corn straw in China: A case study in Jilin Province. Energy 2017, 130, 373-381. [CrossRef]

33. European Standard Commision. Environmental Management_Life Cycle Assessment_Principles and Framework (ISO 14040:2006); ISO: Geneva, Switzerland, 2006.

34. European Standard Commision. Environmental Management_Life Cycle Assessment_Requirements and Guidelines (ISO 14044:2006); ISO: Geneva, Switzerland, 2006.

35. Weidema, B.P.; Bauer, C.; Hischier, R.; Mutel, C.; Nemecek, T.; Reinhard, J.; Vadenbo, C.O.; Wernet, G. Overview and Methodology. Data Quality Guideline for the Ecoinvent Database Version 3; Technical Report; The Ecoinvent Centre: St. Gallen, Switzerland, 2013

36. Martin, S.; Bunsen, J.; Ciroth, A. Case Study Ceramic Cup vs. Paper Cup; Technical Report; GreenDelta GmbH: Berlin, Germany, 2018.

37. Masella, P.; Galasso, I. A Comparative Cradle-to-Gate Life Cycle Study of Bio-Energy Feedstock from Camelina sativa, an Italian Case Study. Sustainability 2020, 12, 9590. [CrossRef]

38. Ecoinvent 3.7.1 Dataset Documentation. Silicon Carbide Production; The Ecoinvent Centre: St. Gallen, Switzerland, 2007.

39. Ecoinvent 3.7.1 Dataset Documentation. Wood Pellet Production; The Ecoinvent Centre: St. Gallen, Switzerland, 2013.

40. Istat, Istituto Nazionale di Statistica. Available online: https:/ / www.istat.it/en/ (accessed on 2 July 2021).

41. Stavropoulos, P.; Giannoulis, C.; Papacharalampopoulos, A. Life cycle analysis: Comparison between different methods and optimization challenges. Procedia CIRP 2016, 41, 626-631. [CrossRef]

42. Kim, S.; Park, J. Comparative life cycle assessment of multiple liquid laundry detergent packaging formats. Sustainability 2020, 12, 4669. [CrossRef]

43. Blandino, M.; Calcagno, M.; Ferrero, C.; Fabbri, C.; Vanzetti, C.; Reyneri, A. Tutolo, Sottoprodotto del Mais per uso Energetico ; L'Informatore Agrario: Verona, Italy, 2013; pp. 11-15.

44. Finkbeiner, M.; Inaba, A.; Tan, R.B.H.; Christiansen, K.; Klüppel, H.J. The New International Standards for Life Cycle Assessment: ISO 14040 and ISO 14044. Int. J. Life Cycle Assess. 2006, 11, 80-85. [CrossRef]

45. Luo, L.; Voet, E.V.D.; Huppes, G. Allocation issues in LCA methodology: A case study of corn stover-based fuel ethanol. J. Life Cycle Assess. 2009, 14, 529-539. [CrossRef]

46. Hauschild, M.; Goedkoop, M.; Guinee, J.; Heijungs, R.; Huijbregts, M.; Jolliet, O.; Margni, M.; De Schryver, A.; Pennington, D.; Pant, R.; et al. Recommendations for Life Cycle Impact Assessment in the European Context_Based on Existing Environmental Impact Assessment Models and Factors (International Reference Life Cycle Data System-ILCD Handbook); Publications Office of the EU: Brussels, Belgium, 2011. [CrossRef]

47. Solomon, S.; Qin, D.; Manning, M.; Chen, Z.; Marquis, M.; Averyt, K.B.; Tignor, M.; Miller, H.L. (Eds.) IPCC 2007: Climate Change 2007: The Physical Science Basis. Contribution of Working Group I to the Fourth Assessment Report of the Intergovernmental Panel on Climate Change; Cambridge University Press: Cambridge, UK; New York, NY, USA, 2007; 996p.

48. Frischknecht, R.; Editors, N.J.; Althaus, H.J.; Doka, G.; Dones, R.; Heck, T.; Hellweg, S.; Hischier, R.; Nemecek, T.; Rebitzer, G.; et al. Overview and Methodology; Technical Report 1; The Ecoinvent Centre: St. Gallen, Switzerland, 2007.

49. Frischknecht, R.; Wyss, F.; Knopfel, S.B.; Luetzkendorf, T.; Balouktsi, M. Cumulative energy demand in LCA: The energy harvested approach. Int. J. Life Cycle Assess. 2015, 20, 957-969. [CrossRef] 